\section{OBSERVAÇÃO PARTICIPANTE E NÃO \\ PARTICIPANTE: CONTEXTUALIZAÇÃO TEÓRICA E SUGESTÃO DE ROTEIRO PARA APLICAÇÃO DOS MÉTODOS}

Objetivo do estudo: Fornecer explicações sobre os métodos, sugerir um roteiro, não exaustivo, e exemplos de utilização dos métodos na etapa de coleta de dados para estimular a utilização dos métodos.

Metodologia/abordagem: Revisão teórica sobre os métodos; Proposta de roteiro de procedimentos para etapa de coleta de dados; Exemplos empíricos de aplicação do método.

Principais resultados: Localização contextual e longitudinal sobre a evolução do método e o emprego da TI na observação não participante; caracterização dos tipos de pesquisadores; detalhamento didático por meio de roteiro (passo a passo) para utilização dos métodos; exemplos empíricos para facilitar a compreensão de utilização dos métodos;

Contribuições teóricas/metodológicas: A principal contribuição foi a proposição de um roteiro (passo a passo) para orientar e estimular os pesquisadores a utilizarem os métodos; A contribuição teórica deita-se sobre a distinção do método de observação participante sobre o pressuposto da etnografia, além da caracterização do método de observação não participante com auxilio da TI. Também, contribuímos tipificando e apontando competências esperadas dos pesquisadores no papel de observadores.

Relevância/originalidade: Proporcionar um roteiro didático, técnico e detalhado aos pesquisadores da área de Estratégia como Prática e/ou Estudo Organizacionais de aplicação de um método que ainda é pouco utilizado, mas que é central nas perspectivas futuras de análises qualitativas da área.

\section{Marcio Luiz Marietto}

Doutor em Administração pela Universidade Nove de Julho - UNINOVE. Pós-doutorando em Estratégia Organizacional pelo globADVANTAGE - Center of Research in International Business \& Strategy. ESTG Instituto Politécnico de Leiria, Portugal. Brasil. E-mail: profmarcioluiz@uol.com.br

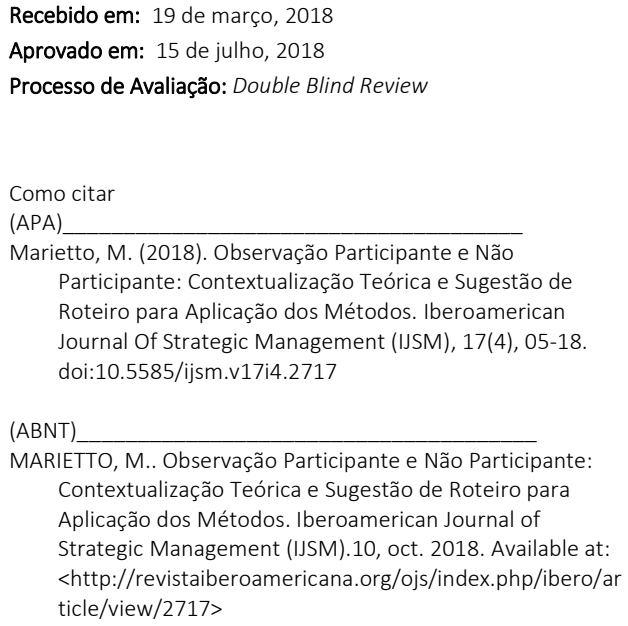




\section{PARTICIPANT AND NON-PARTICIPANT OBSERVATION: THEORETICAL CONTEXTUALIZATION AND GUIDE SUGGESTION FOR METHODS APPLICATION}

Objective: Our objective was to provide explanations about methods, and to suggest a non-exhaustive road map with examples methods at the data collection stage of the research, in order to encourage the use of methods.

Method: Theoretical review on methods; proposition of a road map of procedures for the data collection stage; empirical examples of method application.

Main results: We found contextual and longitudinal location on the evolution of the method and the use of IT in non-participant observation. We also identified a characterization of the types of researchers, didactic detail by means of a script (step by step) in methods use, and empirical examples to understand the use of methods.

Theoretical / methodological contributions: The main contribution was the proposition of a script (step by step) to guide and stimulate the researchers to use the methods. The theoretical contribution is based on the distinction of the method of participant observation on the assumption of ethnography, besides the characterization of the method of non-participant observation with the help of IT. Also, we contribute by typifying and pointing out the expected competencies of the researchers as observers.

Relevance / originality: This work provides a didactic, technical and detailed guide to researchers in Strategy as Organizational Practice and / or Study area, applying a method that is still little used but which is essential to the future perspectives of qualitative analysis.

\section{OBSERVACIÓN PARTICIPANTE Y NO PARTICIPANTE: CONTEXTUALIZACIÓN TEÓRICA Y SUGERENCIA DE GUION PARA LA APLICACIÓN DE LOS MÉTODOS}

Objetivo del estudio: Proporcionar explicaciones sobre los métodos, sugerir un guion, no exhaustivo, y ejemplos de utilización de los métodos en la etapa de recolección de datos para estimular la utilización de los métodos.

Metodología / enfoque: Revisión teórica sobre los métodos; Propuesta de plan de procedimientos para la etapa de recolección de datos; Ejemplos empíricos de aplicación del método.

Principales resultados: Localización contextual y longitudinal sobre la evolución del método y el empleo de la TI en la observación no participante; caracterización de los tipos de investigadores; detallado didáctico por medio de un itinerario (paso a paso) para la utilización de los métodos; ejemplos empíricos para facilitar la comprensión de la utilización de los métodos;

Contribuciones teóricas / metodológicas: La principal contribución fue la propuesta de un itinerario (paso a paso) para orientar y estimular a los investigadores a utilizar los métodos; La contribución teórica se acentúa sobre la distinción del método de observación no participante sobre el presupuesto de la etnografía, además de la caracterización del método de observación no participante con auxilio de la TI. También, contribuimos tipificando y apuntando competencias esperadas de los investigadores en el papel de observadores.

Relevancia / originalidad: Proporcionar un itinerario didáctico, técnico y detallado a los investigadores del área de Estrategia como Práctica y / o Estudio Organizacionales de aplicación de un método que aún es poco utilizado, pero que es central en las perspectivas futuras del análisis cualitativo del área. 


\section{INTRODUÇÃO}

No contexto brasileiro o método de observação participante é utilizado com frequência nas ciências da saúde e na sociologia. A Administração de Empresas, com prevalência nos Estudos Organizacionais e na disciplina de Estratégia como Prática, estão iniciando a aderência à técnica, todavia, no Brasil, os estudos ainda são escassos. No contexto internacional, nas ultimas décadas, o impacto da Tecnologia da Informação (TI) tornou possível o estudo das características da vida social por meio da utilização de gravações de vídeo (observação não participante). Esta ascensão do uso da observação participante e não participante esta mudando as ciências sociais, em especial os achados científicos na Administração de Empresas (LeBaron, Jarzabkowski, Pratt \& Fetzer, 2018).

Os métodos de observação participante e não participante estão se tornando uma ferramenta de pesquisa priorizada por muitos pesquisadores no campo dos estudos organizacionais. Contudo, a utilização destas técnicas ainda são escassas e a técnica de observação com o auxilio de vídeo é relativamente nova no campo (LeBaron et al., 2018). Este artigo tem como objetivo fornecer explicações sobre os métodos, sugerir um roteiro, não exaustivo, e exemplos de utilização dos métodos na etapa de coleta de dados para estimular a utilização dos métodos.

A escassez de estudos com estes métodos na área de Administração de Empresas fez com que utilizássemos alguns pouquíssimos estudos disponíveis no campo no contexto nacional e internacional. Os estudos que serviram de base foram escolhidos por se tratarem dos estudos mais recentes e relevantes ao campo. Eventualmente, para uma melhor contextualização da etapa de coleta de dados das técnicas, principalmente na elaboração do roteiro (guide) e nos exemplos, utilizamos, também, estudos de outras áreas. Os exemplos de aplicação da etapa de coleta de dados foram rigorosamente transcritos não demandando nenhuma análise de nossa parte. Ressaltamos que nossa intenção é a proposta de um roteiro somente para a etapa de coleta de dados. Um roteiro para a contextualização da etapa de análise de dados das técnicas demandaria outro estudo devido as suas características, complexidade e extensão.

Este artigo divide-se na explicação do que é a observação participante. Em seguida adentramos a evolução tecnológica do método e a observação não participante. Após, fomentamos a tipificação e as competências esperadas do observador que culminam na sugestão de um roteiro de aplicação para a etapa de coleta de dados. Finalmente, disponibilizamos, como exemplos, alguns estudos que utilizaram os procedimentos de observação participante e não participante.

\section{O QUE É OBSERVAÇÃO PARTICIPANTE}

Iniciamos às explicações sobre o método com uma contextualização teórica para tentar dirimir uma frequente confusão que ocorre com estudantes e pesquisadores: a diferença entre etnografia e observação participante - ambas muitas vezes são tratadas como sinônimos, o que é incorreto. De forma genérica e não exaustiva Angrosino (2009) enfatiza que "etnografia significa literalmente a descrição de um povo". A proposta esta no estudo de grupos organizados, na coletividade de indivíduos em determinado arranjo social. A pesquisa busca absorver as peculiaridades culturais desta comunidade por meio da apuração dos processos de interação social. Para esta absorção tentam-se sistematizar os comportamentos, costumes, crenças, além de outras dimensões e elementos culturais compartilhados pelos indivíduos. De forma mais abrangente, a etnografia - do grego ethos (cultura) + graphe (escrita) - é parte integrante da etnologia. A etnografia prevê diversos métodos como, por exemplo, escavações arqueológicas que podem tentar revelar dados etnográficos de culturas ancestrais; entrevistas em profundidade para reconstrução de memoria histórica; análises documentais históricas; semiótica; análise de discurso e conteúdo, entre outros métodos, além da própria observação participante.

A observação participante é um método qualitativo com raízes na pesquisa etnográfica tradicional. O termo foi usado pela primeira vez pelo antropólogo social Malinowski na década de 1920 e a abordagem foi posteriormente desenvolvida pela Escola de Chicago sob a liderança de Robert Park e Howard Becker (Given, 2008; Mack, Woodsong, Macqueen, Guest \& Namey 2005). Essa abordagem permite ao pesquisador (fieldworker) utilizar o contexto sociocultural do ambiente observado (os conhecimentos socialmente adquiridos e compartilhados disponíveis para os participantes ou membros deste ambiente) para explicar os padrões 
observados de atividade humana. Ou seja, consiste na inserção do pesquisador no interior do grupo observado, tornando-se parte dele, interagindo por longos períodos com os sujeitos, buscando partilhar o seu cotidiano para sentir o que significa estar naquela situação (Marietto \& Sanches, 2013; Given, 2008; Queiroz, Vall, Alves e Souza \& Vieira, 2007; Van Maanen, 1979).

O objetivo da observação participante é produzir uma "descrição densa" da interação social em ambientes naturais. Ao mesmo tempo, os informantes são incentivados a usar sua própria linguagem e conceitos diários para descrever o que está acontecendo em suas vidas esperando-se, que no processo, emerja uma imagem mais adequada do contexto de investigação como um sistema social descrito a partir de uma série de perspectivas dos participantes (Marietto \& Sanches, 2013). Outro objetivo é obter uma compreensão profunda de um tema ou situação particular por meio dos significados atribuídos ao fenômeno pelos indivíduos que o vivem e experimentam. Em geral, a observação participante ocorre em ambientes comunitários ou em locais que se acredita ter alguma relevância para as questões de pesquisa. $\mathrm{O}$ método é diferenciado porque o pesquisador se aproxima dos participantes da pesquisa em seu próprio ambiente. Assim, de um modo geral, o pesquisador envolvido na observação participante tenta aprender como é a vida de um "nativo", mantendo-se, inevitavelmente, um "estranho" (Mack et al., 2005).

O método de coleta de dados na observação participante consiste na participação do pesquisador nas atividades cotidianas relacionadas a uma área da vida social, a fim de estudar aspectos de vida por meio da observação de eventos em seus contextos naturais (Given, 2008). O pesquisador, na observação participante, coleta dados por meio da participação na vida cotidiana das pessoas que ele ou ela está estudando. A abordagem está na interação cotidiana envolvendo conversas para descobrir as interpretações dos participantes nas situações que estão envolvidos. O método é especialmente adequado para o estudo de fenômenos sociais sobre o qual pouco se conhece e onde o comportamento de interesse não está prontamente disponível para visualização pública. Portanto, os pesquisadores buscam compreender o fenômeno por meio da observação por si só, ou observando e participando, em diferentes graus, nas atividades diárias da comunidade, grupo ou contexto estudado (Given, 2008; Mac An Ghaill, 1994). O método completo de observação participante constitui uma estratégia de campo abrangente na medida em que "combina simultaneamente a análise de documentos, entrevistas aos participantes e informantes, a participação direta, a observação e a introspecção". Exemplificando, normalmente, os pesquisadores da área da antropologia combinam seus dados com notas de campo, observação testemunhal, informações obtidas a partir de informantes, entrevistas informais e descrições dos "nativos" ou informantes. $\mathrm{O}$ pesquisador emprega múltiplas e sobrepostas estratégias de coleta de dados a serem totalmente engajadas em experimentar (sentir ou vivenciar) o arranjo contextual (a participação), enquanto que, ao mesmo tempo em que observa e conversa com outros participantes sobre o que está acontecendo (Patton, 2002).

\section{EVOLUÇÃO TECNOLÓGICA DO MÉTODO E A OBSERVAÇÃO NÃO PARTICIPANTE}

Como observamos, o método tem suas raízes no final do século XIX e inicio do século XX. A humanidade e, consequentemente, as sociedades evoluíram. Na esteira da revolução industrial criaram-se novos aspectos sociais, como por exemplo, a vida inserida na sociedade das organizações. Estas organizações, de cunho capitalista ou não, nos proporcionaram avanços tecnológicos ao mesmo tempo em que iniciaram novas demandas por estudos sociais. Em geral, as organizações são compostas por inter-relações sociais individuais e grupais complexas diárias e suas atividades laborais (formais e/ou informais) estão inseridas em um ambiente altamente técnico e institucionalizado (Marietto \& Serra, no prelo).

Os procedimentos pautados na observação participante e utilizados nas pesquisas organizacionais buscam captar o ambiente técnico e institucional do fenômeno em observação. Assim, o como fazer a pesquisa etnográfica no campo organizacional tende a ensejar uma série de processos e instrumentos de coleta de dados tidos, talvez, como modernos. Estes instrumentos e processos estão à revelia dos cadernos, penas e lápis pitorescos utilizados por Malinowski ou Frans Boas, entre outros tantos pesquisadores em seus apontamentos sobre suas observações. Anteriormente, o pesquisador era obrigado a fazer uso excessivo de suas capacidades de memoria e memorização, pois os ambientes investigados tendem a ser dinâmicos e, muitas vezes, a mão que escreve tende a não acompanhar a velocidade dos acontecimentos forçando o pesquisador a fazer uso 
de sua memória na reconstrução dos fatos para suas anotações. Memoria esta que, por vezes, poderia falhar (Marietto \& Sanches, 2013; Geertz, 1993).

Atualmente, de forma diferente do passado, o pesquisador pode se utilizar da Tecnologia da Informação como principal ferramenta para impor o rigor e veracidade dos dados coletados e, posteriormente, analisados. Esta utilização da TI na observação participante esta sendo tratada na literatura como Observação Não Participante (Nonparticipant Observation) (LeBaron et al., 2018; Marietto \& Maccari, 2015; Liu \& Maitlis, 2014; Liu \& Maitlis, 2010; LeBaron 2008; Caldwell \& Atwal, 2005). O pesquisador deve se valer de ferramentas primárias de pesquisas como gravadores em áudio e/ou vídeo, além da utilização de outras formas eletrônicas para as notas como laptops, notebooks, celulares, entre outros. Outros aparatos eletrônicos como ferramentas secundárias de pesquisa também podem ser utilizados para a complementação das notas de campo. Instrumentos como videoteipes, audioteipes, fotografias, além de documentos que podem ser coletados no campo como brochuras, reportagens, panfletos, arquivos, documentos institucionais, cartões de visita, reportagens, acesso a sites entre outros tantos. Porém, ressalta-se que estes servem como complemento, pois a principal atenção recai sobre a interação pessoal do pesquisador com os indivíduos, grupo e contexto técnico institucional encontrado no ambiente de pesquisa (LeBaron et al., 2018; Marietto \& Maccari, 2015; Liu \& Maitlis, 2014; Liu \& Maitlis, 2010; LeBaron, 2008; Caldwell \& Atwal, 2005; Samra-Fredericks, 2000).

A Observação Não Participante com o uso da TI tende a diminuir diversas limitações do método de Observação Participante. Diversas inferências de limitações quanto ao método que poderiam ser feitas em relação aos dados coletados tendem a se desmancharem à medida que a TI ajuda na triangulação da originalidade dos fatos. Em poucas palavras, as restrições e limitações da utilização do método de Observação Participante na coleta e análise de dados primários podem ser sumarizadas como a dificuldade em delimitar geograficamente e, muitas vezes, socialmente o indivíduo ou grupo a ser estudado. Eventualmente, os indivíduos ou grupos podem não estar localizados geograficamente e socialmente nos mesmos ambientes dificultando a generalização dos dados colhidos, uma vez que o pesquisador não pode estar presente em todos os ambientes ao mesmo tempo. Outro ponto é a dificuldade que se apresenta quando a língua nativa é diferente da língua do pesquisador que, naturalmente, deverá aprender para que se possibilite uma interação adequada. Em consequência, com o aumento das possibilidades e capacidades de gravação e uso de equipamentos eletrônicos muitas restrições como vieses interpretativos ou a ausência de possibilidades de se verificar se o que foi realmente apurado ou falado no campo foi realmente elucidado são eliminadas (LeBaron et al., 2018; Marietto \& Maccari, 2015; Liu \& Maitlis, 2014; Liu \& Maitlis, 2010; LeBaron, 2008; Caldwell \& Atwal, 2005; Samra-Fredericks, 2000).

Contudo, a principal limitação, de todas as pesquisas de cunho observacional, permanece: a própria apresentação do trabalho. A leitura que o pesquisador faz da realidade contextual será sempre sobre os ombros dos outros (Geertz, 1993) e somente estes podem atribuir o verdadeiro significado da realidade vivenciada por eles. Consequentemente, pode-se inferir que a transcrição da experiência, seja para o texto ou para outro tipo de instrumento eletrônico, ou não, tende a uma dupla limitação: a) a de não se alcançar o real significado do fenômeno de análise sobre a perspectiva do indivíduo ou grupo observado; e b) a de não ser possível transcrever, gravar ou repassar todo o significado e aprendizagem obtidos no momento da pesquisa no campo ao público interessado. Isto se deve pela limitação condicionada pelo momento e a potência instantânea do acontecimento factual, ou pela limitação do pesquisador em interpretar e repassar as nuances factuais em sua forma de potencialidade instantânea (Samra-Fredericks, 2000; Geertz, 1993). Porém, a utilização da TI na observação não participante proporciona maior rigor a análise e aos resultados da observação. A possibilidade de poder ver e rever repetidamente e cuidadosamente o evento possibilita ao pesquisador identificar padrões de interação que fornecem uma base robusta para o rigor empírico.

\section{TIPIFICAÇÃO E AS COMPETÊNCIAS ESPERADAS DO OBSERVADOR: SUGESTÃO DE UM ROTEIRO DE APLICAÇÃO PARA A ETAPA DE COLETA DE DADOS}

Optamos por adaptar a tipologia de Gold (1958) mediante a intenção do grau de envolvimento que o observador pretende tomar no 
decurso da pesquisa em campo. Esta tipificação torna evidente a diferença entre observador $\mathrm{e}$ participante durante o processo de coleta e análise de dados.

Participante Completo - o pesquisador entra no ambiente sem revelar qual é o seu objetivo ou mesmo sua identidade verdadeira tentando tornar-se um dos membros rotineiros do grupo mantendo-se como um observador disfarçado. Seu interesse científico é completamente desconhecido do grupo. O pesquisador é, de certa forma, forçado a desempenhar um papel condizente com a estrutura social do grupo. Por exemplo, um pesquisador que pretende observar as interações sociais de uma torcida de um time de futebol interage com a mesma na forma de torcedor e não se identificando como pesquisador. Ressaltamos que, eventualmente, e observadas às regras éticas de cada área do conhecimento, aproveitando-se da TI gravações não reveladas podem ser realizadas neste tipo de pesquisa. Contudo, ressaltamos a consulta rigorosa às regras de procedimentos éticos de cada área do conhecimento, uma vez que existem variações de permissão deste método dentro das diversas áreas do conhecimento.

Participante como Observador - neste contexto o pesquisador negocia e obtém um consentimento prévio do grupo para poder observalos e realizar o estudo. Ou seja, o grupo esta ciente da sua presença e seus objetivos, e com o passar do tempo tende a ser "aceito" pelo grupo. Com o aumento da confiança a pesquisa tende a se desenvolver com mais eficácia. Como exemplo, temos o estudo de Marcon e Elsen (2000) relatado abaixo.

Observador como Participante - Neste caso, o observador tem envolvimento mínimo no contexto social estudado. Existe algum tipo de conexão com o grupo ou contexto, mas o observador não é naturalmente ou normalmente parte do ambiente social. Em geral, como exemplo, temos as pesquisas organizacionais, onde, muitas vezes, o pesquisador identifica-se como tal, contudo apenas observa o andamento das rotinas laborais sem envolver-se diretamente nas mesmas. Exemplos referem-se a observações feitas nas áreas operacionais das organizações (produção) ou nos acompanhamentos de reuniões do alto escalão.

Observador Completo - O pesquisador não participa de nenhuma forma do contexto social do grupo. O pesquisador que opta pela observação não participante com o auxilio da TI inclui-se neste tipo. Como exemplo, observam-se estudos na área da psicologia e psiquiatria em que se observam o comportamento social de crianças interagindo através de um vidro espelhado. Em outro ponto temos as gravações em vídeo e áudio de reuniões no alto escalão das empresas para posterior análise.

Adaptamos, também, a lista de Queiroz et al., (2007) sobre algumas das competências e habilidades esperadas do pesquisador para a realização da observação participante e não participante. Sugere-se que caso o pesquisador não atenda a (no máximo) dois dos quesitos abaixo opte por outro método ou solicite a ajuda de um pesquisador mais experiente na área de observação.

- Ser capaz de estabelecer uma relação de confiança com os sujeitos;

- Ter sensibilidade para pessoas e seus comportamentos físicos, psíquicos e sociais;

- Ser um bom ouvinte;

- Ter conhecimento profundo dos procedimentos éticos em sua área de pesquisa;

- Ter boa capacidade de memoria mesmo utilizando recursos de TI;

- Ter familiaridade com as questões investigadas como preparação teórica sobre o objeto/fenômeno de estudo ou situação que será observada;

- Possuir amplo conhecimento da amostra para delimitação física, geográfica e social;

- Possuir amplo conhecimento dos riscos físicos, psíquicos e sociais que a imersão em campo pode proporcionar e preparar-se cuidadosamente para evita-los;

- Ter flexibilidade para se adaptar a situações inesperadas;

- Não ter pressa de adquirir padrões ou atribuir significado aos fenômenos observados;

- Se utilizar recursos de TI ter profundo conhecimento técnico sobre os mesmos;

- Elaborar um plano sistemático e padronizado para observação e registro dos dados;

- Possuir planos de contenção para eventualidades inesperadas durante a observação ou no uso dos recursos de TI (quando for o caso); 
- Ter habilidade em aplicar instrumentos adequados para a coleta e apreensão dos dados;

- Verificar e controlar os dados observados;

- Ser rigoroso nas anotações, tipificação e contextualização dos dados observados;

- Ter conhecimento profundo em métodos de pesquisa complementares à observação (análise de documentos, análise de conteúdo, análise de discurso, entre outros) para a validação e rigor das análises; e

- Capacidade apurada de interpretação para relacionar os conceitos e teorias científicas aos dados coletados.

A tipificação e as competências esperadas do pesquisador forneceram os elementos para a sugestão de um roteiro, não exaustivo, para operacionalização da etapa de coleta de dados do método. Não existe, ainda, um consenso entre os autores mais relevantes na área da pesquisa qualitativa sobre um roteiro pré-estabelecido para os procedimentos operacionais na observação participante e não participante. $\mathrm{O}$ ambiente $\mathrm{e}$ mesmo a disponibilização dos grupos ou situações a serem observadas podem variar de forma bastante extensa. Desta forma, utilizamos os prescritos de Marietto e Maccari (2015); Liu e Maitlis (2010); LeBaron (2008); Queiroz et al., (2007); Valadares (2007); e Mack et al., (2005) para compor e propor um pequeno roteiro de preparação e realização da observação participante e não participante. A intenção é tentar auxiliar o leitor em suas futuras incursões a campo. Entretanto, deve-se observar que é apenas uma proposta generalista, uma vez que podem existir variações de procedimentos dependendo da especificidade dos contextos, ambientes e/ou grupos a serem observados.

\section{Antes de ir a campo:}

- Determine o propósito da atividade de observação relacionando-os com os objetivos gerais da pesquisa;

- Determine a(s) população(ões), a(s) delimitação(ões) física(s) e social(is) a $\operatorname{ser}(\mathrm{em})$ observada(s)

- Analise a acessibilidade da(s) população(ões), o(s) local(is) e o(s) contexto(s)em que você gostaria de observá-los.

- Tente definir qual tipo de observador você pretende enquadrar-se para desempenhar as observações;
- Se a opção for pela observação não participante, estude com profundidade e rigor quais aparatos tecnológicos melhor se adaptam ao contexto da pesquisa;

- Investigar antecipadamente os possíveis locais para a observação;

- Selecione o(s) contexto(s), hora(s), data(s) e antecipe-se quanto tempo você irá coletar dados de observação em cada incursão;

- Pense em como você vai apresentar-se, inclusive em termos de aparência, e como você vai explicar o seu propósito de pesquisa para os outros, se necessário;

- Planeje antecipadamente como você pretende tomar notas e apurar os contextos sociais durante a atividade de observação (utilização de recursos audiovisuais - se possível e necessário);

- Tenha em mente o ponto exato (tempo em campo versus quantidade de dados) de encerrar a observação (participante ou não) em campo;

- Crie planos de contenção para eventuais impossibilidades de observação sujeitas ao local físico, com os indivíduos ou com os aparatos tecnológicos (se for o caso);

\section{Em Campo}

- Tenha cautela e polidez ao aproximar-se do(s) indivíduo(s) e/ou grupo a ser observado;

- Se for o caso, informe e negocie sua entrada e permanência em campo, seja como observador participante ou não participante;

- Na observação participante é preciso ter sensibilidade sobre quando perguntar e quando não perguntar. O ideal é não perguntar nada e evitar interferência. Interferência ou perguntas devem ser o ultimo recurso;

- As entrevistas formais devem ser evitadas; O procedimento é de observação e não entrevista. Para entrevistas existem métodos específicos;

- Tome notas detalhadas de todas as situações que você considera relevante para seus objetivos de pesquisa;

- Identifique claramente o contexto social dos indivíduos observados (ex: chefe; proprietário; familiar, entre outros). Este detalhe terá forte impacto no momento da análise dos dados;

- Se necessário, possível e dentro do pressuposto ético recorra a TI (gravadores de áudio e som) para auxiliar na obtenção das notas de campo;

- As notas de campo devem incluir relatos de eventos, como as pessoas se comportam e reagem, o que foi dito na conversa, quem disse, onde as 
pessoas foram posicionados em relação ao outro, suas idas e vindas, gestos físicos, suas respostas subjetivas e todas as outras informações e observações necessárias para tornar a história da experiência de observação completa. Elas devem ser marcadas com posições temporais no caso de gravações.

- Notas de campo devem ser escritos de forma discreta durante a observação participante ou após a atividade, dependendo de onde você vai e quanto tempo você participar;

- Se for importante para a pesquisa destaque e contextualize as notas que possuem comportamentos não verbais;

- No caso da observação com utilização dos recursos de TI instale-os e teste os equipamentos de forma antecipada;

- Durante a instalação e teste dos equipamentos procure as posições físicas mais vantajosas para as gravações;

- Na observação não participante, depois de ligados os equipamentos, tente não interferir no processo de gravação durante o período de observação;

- Na observação não participante mesmo que o equipamento, por algum motivo, pare de funcionar ou tenha algum tipo de problema, sugerese que o pesquisador não invada o ambiente no momento do acontecimento dos fatos. A simples invasão para, eventualmente, reposicionar, religar ou até mesmo trocar uma bateria pode interferir no contexto ambiental dos fatos e gerar desagrado e desconfiança do(s) individuo(s) e/ou grupo;

- A rotina do observador será fundamental para gerar confiança na população estudada. Sabese que os indivíduos e/ou populações tendem a adaptar seus comportamentos quando tem ciência que estão sendo observados. A presença rotineira do pesquisador, ao longo do tempo, tende a desencadear o comportamento natural dos observados;

\section{Imediatamente, logo após deixar o Campo}

- Sempre planeje um tempo para revisar e expandir suas notas logo após o retorno do campo;

- Seja qual for o caso, as notas devem ser expandidas (tratadas analiticamente mediante os objetivos da pesquisa) o mais rápido possível antes que os detalhes contidos em sua memória se percam. Existem recomendações que o tempo máximo deve ser de 3 horas após deixar o campo para iniciar a revisão e análise das notas;

- No caso de utilização de gravadores visuais ou de voz, sempre que possível, reveja a gravação imediatamente após o termino e realize notas temporais categorizando os períodos de acordo com suas necessidades de pesquisa;

- Transcreva e digitalize o quanto antes as gravações incluindo marcos temporais e as notas de comportamentos não verbais;

- Digite suas notas no computador utilizando o formato padrão que você pretende usar na apresentação e análise de seus dados;

- Se necessário utilize softwares (por exemplo, AtlasTi - ver Costa e Itelvino, 2018) para ajudá-lo na organização de suas notas e procedimentos analíticos, independente do tipo de observação;

- Sempre que possível, para um maior rigor e confiabilidade da pesquisa, realize a triangulação dos dados obtidos em campo por meio de outras fontes que comprovem os fatos apurados. Procure utilizar documentos, atas, matérias de jornais, entrevistas e/ou conversas com outros pesquisadores e/ou especialistas do mesmo assunto, entre outras formas.

\section{ALGUNS EXEMPLOS EMPÍRICOS}

Nesta seção sumarizamos alguns estudos que utilizaram os procedimentos de observação participante e não participante. $O$ objetivo é demonstrar aos estudantes e pesquisadores a forma de operacionalização dos métodos de coleta de dados em campo. Embora, nosso foco seja a Administração de Empresas, iniciamos com a aplicação em outras áreas para demonstrar que a operacionalização dos métodos é muito semelhante, independente da área do conhecimento. Assim, por conveniência e restrição de espaço, oferecemos dois exemplos de observação participante em outras áreas do conhecimento e dois exemplos de observação não participante na área de administração de empresas. A principal sugestão deita-se na intenção de que para total compreensão dos contextos de operacionalização os estudantes e pesquisadores devem consultar as obras em seu inteiro teor. Ressaltamos que este artigo tem o objetivo de fornecer um guia para a coleta de dados por meio da observação participante e não participante. Para explicar os procedimentos de análise dos dados seria necessário outro estudo.

A ciência da saúde em suas diversas áreas como enfermagem, nutrição, medicina, saúde pública e coletiva, saúde mental, entre outras se apresentam como grande utilizadora e beneficiárias da observação participante em seus estudos. Os resultados produzidos são relevantes para o conhecimento, pois possuem alto rigor e 
confiabilidade em seus métodos de coleta e análise de dados. Um exemplo desta apropriação encontrase no trabalho de Marcon (1989), que teve por objetivo compreender o período de gestação a partir da percepção das mulheres em estado de gravidez. Posteriormente, Marcon e Elsen (2000) publicaram: "Estudo qualitativo utilizando observação participante - análise de uma experiência". As pesquisadoras descrevem os principais aspectos relativos à experiência em desenvolver um estudo que utilizou como método de coleta de dados a observação participante. $\mathrm{O}$ artigo evidencia as estratégias utilizadas na aproximação com os informantes, o processo de decisão utilizado e os sentimentos experimentados ao longo do estudo. Deve-se notar, nas citações diretas abaixo, o rigor aos pressupostos conceituais e técnicos relativos ao método da observação participante adotados pelas pesquisadoras.

O papel adotado durante toda a coleta de dados foi o de observadora e participante, variando de observadora como participante e de participante como observadora (Pearsall, 1965). Minha participação foi do tipo conhecida (Lofland, 1971) pelos observados, ou seja, as gestantes que compuseram a amostra foram informadas sobre o estudo e concordaram em participar do mesmo; e a função científica de minha presença foi dada a conhecer a todos os elementos do serviço. Os dados foram coletados no período de outubro de 1986 a julho de 1987, diariamente e no mesmo dia e local no qual a assistência era prestada, utilizando como estratégias observação, entrevistas e consulta a documentos (prontuários das clientes). [...] Ao final, o período de dois meses correspondeu às fases 1 e 2 da observação participante e, portanto, da coleta de dados. Durante esse período, procurei fazer contatos informais com todo o pessoal do serviço e também com algumas gestantes. Pude, ainda apresentar formalmente à enfermeira a proposta do estudo e explanar informalmente sobre meus objetivos aos outros membros da equipe de saúde. [...] No início, sentia-me bastante deslocada e tinha a sensação de estar sendo avaliada tanto pelas pessoas do serviço como pelas clientes. [...] Além disso, como no início ficava do lado de dentro do balcão, para observar como as mulheres eram recepcionadas no serviço, sentia-me muito mal em ficar ali sem fazer nada, principalmente quando acontecia de ficar sozinha, pois as mulheres chegavam e, sem dizer nada, estendiam seu cartão de identificação em minha direção. [...] Quando comecei a observar a pré-consulta (na metade da terceira semana no campo), já me havia habituado a observar e já não me sentia tão ociosa. Só comecei a ajudar nesta tarefa porque achava que, assim, haveria maior aproximação com a funcionária responsável por esta atividade e com a própria enfermeira, a quem, às vezes, eu ajudava. [...] ao final do primeiro mês no campo, considerava que meu grande problema era apenas com a enfermeira, com quem não estava conseguindo manter uma relação amigável, pois ainda não havia descoberto uma forma de nos aproximarmos, o que fazia com que a relação profissional se tornasse distante e impessoal. [...] No início da observação dessas atividades, a enfermeira dava-me a impressão de estar se sentindo avaliada, pois, depois que a cliente saía, ela ficava se justificando, dizendo que não dava para fazer isto ou aquilo, por este ou aquele motivo. Eu também, de certa forma, vivia me justificando, pois sentia necessidade de comentar somente coisas específicas da cliente, na tentativa de demonstrar que meu objetivo não era avaliá-la. Aos poucos, nossas conversas, além de se tornarem mais freqüentes, foram extrapolando os temas referentes à profissão. (Marcon \& Elsen, 2000, p. 638639).

$\mathrm{Na}$ antropologia Branislaw Malinowski utilizou a observação participante para os estudos sobre os aborígenes australianos na obra "Os Argonautas do Pacífico Ocidental” em 1921. Outro exemplo de estudo antropológico que utilizou a observação participante encontra-se nos estudos de Margareth Mead sobre as Tribos em Samoa (Coming of Age in Samoa) em 1928. Todavia, a observação participante expandiu-se para outras áreas das Ciências Sociais, como por exemplo, a Sociologia, onde Valadares (2007) descreve, sucintamente, o estudo de William Foote Whyte "Sociedade de esquina: a estrutura social de uma área urbana pobre e degradada":

Originalmente publicado em 1943, um clássico dos estudos urbanos o texto é não apenas atual pela temática que aborda a juventude, a organização social das gangs e dos bairros pobres -, mas também um livro fundamental para aqueles que fazem trabalho de campo nas cidades, realizando o que os norte-americanos denominam anthropology at home. É também de grande importância para os sociólogos urbanos que cada dia aderem mais aos métodos qualitativos e aos estudos de caso e se interessam pelo tema das redes sociais, da juventude, da política local e da territorialização da pobreza. (...) William Foote Whyte, filho de classe média alta norte-americana, pesquisou nos anos de 1930 uma área pobre e degradada da cidade de Boston, onde morava. Conhecido como um dos slums mais perigosos da cidade e sobre o qual circulavam várias idéias preconcebidas $\mathrm{e}$ estigmatizantes, o bairro italiano é pouco a pouco "desbravado" pelo aprendiz de pesquisador que apenas o conhecia por "ouvir dizer". Ao mesmo tempo em que se insere na localidade e vai redefinindo os objetivos de sua pesquisa, dá tropeços no convívio com os moradores, aprendendo a pensar e a refletir sobre a 
natureza de suas relações com os informantes. Aos poucos vai sendo aceito, muda-se inclusive para Cornerville, mas se dá conta de que é fundamental poder contar com um intermediário para realizar sua observação. "Doc", termo que define um informantechave, simboliza esse mediador, que garante o bom acesso à localidade e/ou ao grupo social em estudo. Desempenha também o papel de conselheiro e "protetor", defendendo o pesquisador contra as intempéries e os imponderáveis próprios ao trabalho de campo. Após três anos de convívio e familiaridade com os diferentes grupos informais e instituições que atuavam e estruturavam a área (clubes sociais, centro comunitário, organizações informais etc.), Foote Whyte deixou o bairro para dedicar-se à difícil tarefa de redigir sua obra. Saída difícil e dolorosa para o observador participante, mas facilitada pelo fato de o jovem pesquisador mudar-se para Chicago, onde se inscreve como aluno de doutorado na universidade onde Robert Park havia bem marcado sua passagem. (Valadares, 2007, p-152-153).

A expansão da utilização dos métodos de observação participante nas Ciências Sociais também atingiu a Administração de Empresas. Para exemplos de trabalhos que utilizaram este método sugerimos observar o estudo de Yen-Tsang, Dultrade-Lima e Pretto (2013). Os autores realizaram uma análise bibliométrica de citação e cocitação em estudos de etnografia na área de Administração de Empresas. Embora, nem todos os estudos citados pelos autores tenham utilizado o método de observação participante, existe no artigo um verdadeiro "cardápio" de estudos na área de Administração que podem ser consultados.

Em outro ponto, a disciplina de Estratégia como Prática junto à área de estudos organizacionais utiliza com frequência o método de observação não participante. Um exemplo encontrase no estudo de Liu e Maitlis (2014). As autoras utilizaram a observação não participante para coletar dados em uma empresa produtora de jogos virtuais (games) de médio-porte localizada na região oeste do Canadá. A intenção das autoras foi de apurar como as dinâmicas emocionais dos membros do alto escalão da empresa afetavam os processos de elaboração das estratégias. Para uma melhor compreensão da descrição do procedimento e na possibilidade de que algumas palavras possam não possuir uma tradução fiel ao português optamos por manter as citações no idioma original. Os leitores devem se atentar a este exemplo na direção de uma das sugestões do roteiro acima, onde as autoras realizam o procedimento de observação não participante e após realizam as entrevistas. Ou seja, ressalta-se que o procedimento de observação, participante ou não, não compreende entrevistas.
Our primary data collection method was nonparticipant observation (Gold, 1958). Over a period of three months, one author attended nine weekly meetings, which were all the meetings held in this period of time, as a non-participant observer. She audio and video recorded each meeting and had the audio files transcribed. Video recording is a relatively new method in strategy research, allowing the capture of the micro-behaviours and interactions that are the 'stuff' of strategic practice (Johnson et al., 2007), including fleeting, nuanced, and rich emotional expressions (Cohen, 2010). [...] In this paper we use data from seven meetings. We have excluded one in which the recording technology failed, and one attended by a consultant because it was not a 'normal' meeting. At the end of the observation period, one author also interviewed each of the team members, asking for their reflections on the team and the meetings she had attended. The same author had also attended meetings of other teams in the organization over several months and had interviewed many of their members, which deepened our understanding of the organization and game industry more generally. Our analysis focuses on the dynamics between team members in the meetings, but we drew on the interview data and this author's broader knowledge of the organization in order to supplement and clarify our observational analyses. (Liu \& Maitlis, 2014, p. 206).

Outro exemplo de utilização do método de observação não participante na área de Administração de Empresas, novamente em Estratégia como Prática, encontra-se no estudo de Marietto (2014) e Marietto e Maccari (2015). O estudo foi conduzido dentro de um pressuposto metodológico multimodal de coleta e análise de dados (Streeck, Goodwin \& LeBaron, 2011). Uma das etapas foi realizada por meio de observação não participante. O objetivo do estudo foi o de analisar como os atores sociais (consultores externos e proprietários) de uma Holding brasileira de grande porte interagiam recursivamente com os elementos estruturais, em suas práticas diárias e espaçotemporalmente localizadas, na formação das Estratégias Empresariais. Abaixo, disponibilizamos excertos com suas respectivas marcações e transcrições que serviram para posterior análise.

Neste estudo realizaram-se duas gravações de áudio e vídeo de duas reuniões formais por um integrante presente em ambas as reuniões que envolveram os proprietários da Holding e o conselho consultivo na sede do grupo. Estas reuniões tinham o único objetivo de debater ações estratégicas de médio e longo prazos para a sobrevivência da Holding. As reuniões foram gravadas com espaço temporal de aproximadamente um mês, sendo que a primeira reunião resultou em 3 
Observação Participante e Não Participante: Contextualização Teórica e Sugestão de Roteiro para Aplicação dos

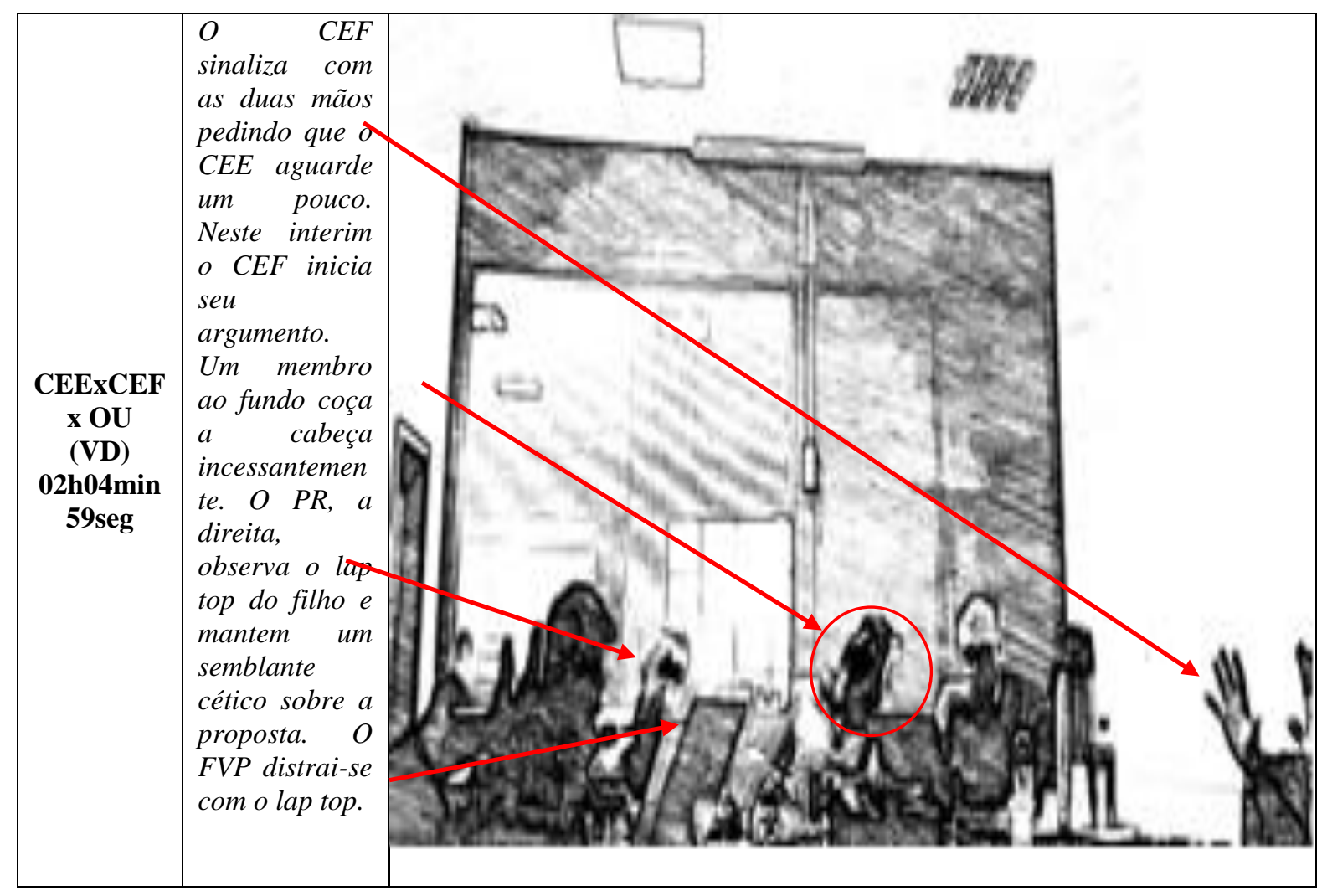

Fonte: Marietto (2014); Marietto e Maccari (2015)

Aos 02h03min09seg o CEE tenta retomar o assunto, imediatamente sem sucesso, pois podese inferir que os demais membros não lhe dão atenção, além de sua própria percepção de que atrapalha o assunto em questão. Percebe-se, mais uma vez, o semblante frustração do CEE. As 02h03min23seg o CEE retoma o assunto conseguihdo manter o foco por mais 1 minuto e dez segundos. Após, o FVP toma a palavra mantem o foco no assunto apresentando, agora, dados sobre alçadas de uma terceir empresa externa. Neste exato momento (02h04min30seg), a câmera é movimentada e consegue-se uma visão privilegiada dos membros da reunião.

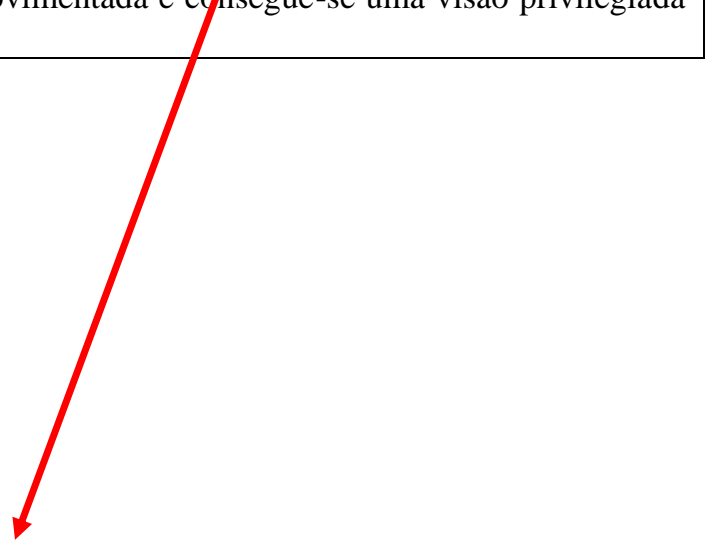




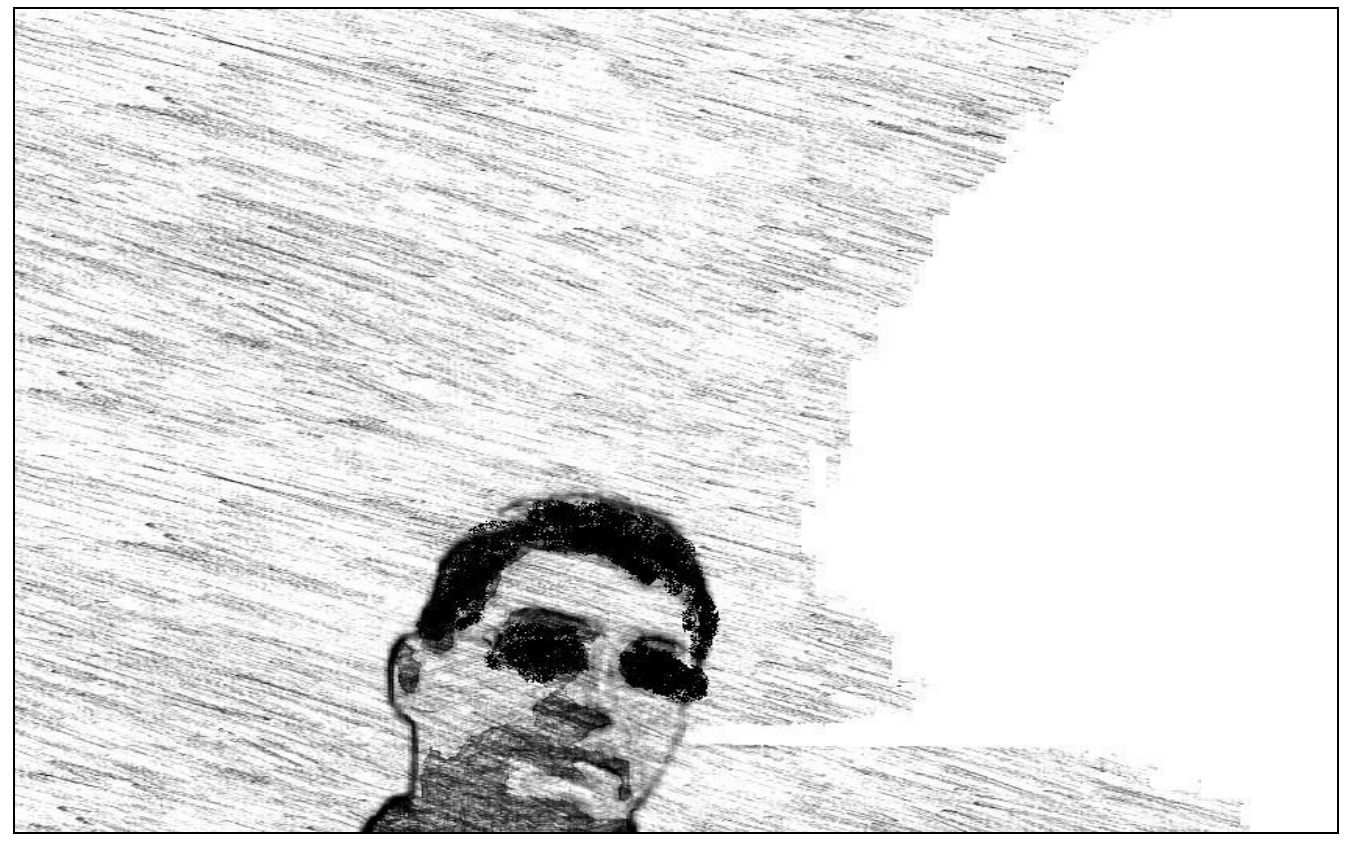

Fonte: Marietto (2014)

\section{CONCLUSÃO}

Concluímos que com a demanda maior por estudos qualitativos na área de Administração de Empresas o método de observação participante vem ganhando espaço, ainda que de forma acanhada. A capacidade do método em demonstrar detalhes de relações sociais entre indivíduos presentes nas organizações parece ser altamente eficaz. Mesmo assim, os estudos que utilizam este método ainda são escassos, principalmente no Brasil. O método de observação participante passou, e esta passando, por um período de incrementação tecnológica que culmina no desenvolvimento do método de observação não participante. $\mathrm{O}$ pesquisador pode se valer de gravações em vídeo e áudio para ampliar a eficácia e o rigor das observações. O pesquisador, também, deve ter em mente que mesmo com os adventos tecnológicos o método de observação participante é puro e único. Em outras palavras, podem-se aglutinar outros métodos (entrevistas, análises de documentos, análises de conteúdo, entre outros) para triangulação dos resultados ou mesmo para aprofundar as análises, mas serão outros métodos e não pertencem ao exercício da observação.

$\mathrm{O}$ roteiro proposto tem o objetivo de estimular a utilização do método. Embora o roteiro ofereça apenas a fase de coleta de dados, pudemos concluir que o pesquisador deve realizar um preparo detalhado e minucioso antes de ir a campo. Os exemplos oferecidos demonstraram a riqueza dos detalhes coletados. Por outro lado, demonstraram, também, as competências e habilidades que os pesquisadores devem possuir para operacionalizar as técnicas em campo. Para estudos futuros sugerimos complementar este roteiro com uma proposta de roteiro sobre a fase de análise de dados nos procedimentos de observação participante e não participante.

\section{REFERENCIAS}

Angrosino, M. (2009). Etnografia e observação participante: coleção pesquisa qualitativa. Porto Alegre: Bookman Editora.

Caldwell, K., \& Atwal, A. (2005). Non-participant observation: using video tapes to collect data in nursing research. Nurse Researcher (through 2013), v.13, n.2, p.42-54.

Costa, P., \& Itelvino, L. (2018). Grounded Theory with the Use of the Atlas.Ti Software: An Empirical Example of a Study on the Ascenting Strategy of Innovative Entrepreneurship in Social Business. Iberoamerican Journal Of Strategic Management (IJSM), 17(3), 14-40. doi: 10.5585/ ijsm.v17i3.2683 
Observação Participante e Não Participante: Contextualização Teórica e Sugestão de Roteiro para Aplicação dos Métodos

Geertz, C. (1993). The interpretation of cultures. London: Fontana Press.

Given, L. M. (2008). The Sage encyclopedia of qualitative research methods, v.1. California: SAGE Publications.

Gold, R. (1958). Roles in sociological field observation. Social Forces, v.36, p.217-223.

LeBaron, C. (2008). Video-Based methods for research on strategy as practice: Looking at people, places and things. Key Note Presented at the Professional Development Workshop: Strategy as Practice: Methodological Challenges. In: $68^{\text {th }}$ Annual Meeting of the Academy of Management. Anaheim: Academy of Management.

LeBaron, C., Jarzabkowski, P., Pratt, M. G., \& Fetzer, G. (2018) An introduction to video methods in organizational research. Organizational Research Methods (ORM), v.21, n.2, p-239-260.

Liu, F., \& Maitlis, S. (2014). Emotional dynamics and strategizing processes: a study of strategic conversations in top team meetings. Journal of Management Studies, v.51, n.2, p.202-234.

Liu, F., \& Maitlis, S. (2010). Non-participant observation. In: Mills, A., Durepos, G., \& Wiebe, E., (eds.). Sage Encyclopedia of case study research. Los Angeles: Sage Publications Ltd.

Mac An Ghaill, M. (1996). Understanding masculinities: social relations and cultural arenas. Buckingham: Open University Press.

Mack, N., Woodsong, C., Macqueen, K. M., Guest, G., \& Namey, E. (2005). Qualitative research methods: a data collector's field guide. North Carolina: Family Health International.

Marcon, S. S. (1989). Vivenciando a gravidez. Tese de Doutorado. Programa de Pós-Graduação em Enfermagem do Centro de Ciências da Saúde. Santa Catarina: UFSC.

Marcon, S. S., \& Elsen, I. (2000). Estudo qualitativo utilizando observação participante análise de uma experiência. Acta Scientiarum, v.22, n.2, p.637-647.
Marietto, M. L., \& Serra, F. (no prelo). The role of institutional elements in strategic activities of small business practitioners. International Journal of Entrepreneurship and Small Business.

Marietto, M. L. (2014). A formação das estratégias organizacionais no conselho consultivo de uma holding: a dualidade da estrutura na visão da Estratégia como Prática. Tese de Doutorado. Programa de Pós-Graduação em Administração. São Paulo, UNINOVE.

Marietto, M. L., \& Maccari, E. (2015). Estudos da Estratégia como Prática na perspectiva estruturacionista: exemplo de contribuição metodológica. Iberoamerican Journal of Strategic Management (IJSM), v.14, n.1, p.90-107.

Marietto, M. L., \& Sanches, C. (2013) Estratégia como prática: um estudo das práticas da ação estratégica no cluster de lojas comerciais da rua das noivas em São Paulo. Revista Pensamento Contemporâneo em Administração, v.7, n.3, p.3858.

Patton, M. Q. (2002). Qualitative research and evaluation (3th ed.). California: SAGE Publications.

Queiroz, D. T., Vall, J., Alves e Souza, A. M., \& Vieira, N. F. C. (2007) Observação participante na pesquisa qualitativa: conceitos e aplicações na área da saúde. Revista Enfermagem UERJ, v.15, n.2, p.276-283.

Samra-Fredericks, D. (2000). Doing Boards-inAction Research: an ethnographic approach for the capture and analysis of directors and senior managers interactive routines. Corporate Governance: An International Review, v.8, n.3, p.244-257.

Streeck, J., Goodwin, C., \& LeBaron, C. (2011). Embodied interaction: Language and body in the material world. Cambridge: Cambridge University Press.

Valadares, L. (2007). Os dez mandamentos da observação participante. Revista Brasileira de Ciências Sociais, v.22, n.63, p.153-155. 
Observação Participante e Não Participante: Contextualização Teórica e Sugestão de Roteiro para Aplicação dos

Van Maanen, J. (1979). The fact of fiction in organizational ethnography. Administrative Science Quarterly, v.24, n.4, p.539-550.

Yen-Tsang, C., Dultra-De-Lima, R. G., \& Pretto, K. (2013). Análise qualitativa das publicações nacionais e internacionais em etnografias em administração e estudos organizacionais. Administração: Ensino e Pesquisa (RAEP), v.14, n.2, p.211-247. 